DOI: $10.15587 / 2706-5448.2021 .237539$

Article type «Reports on Research Projects»

\section{Iryna Kazak}

\title{
IMPROVEMENT OF THE EXTRUDER BODY DESIGN IN ORDER TO INCREASE RELIABILITY AND DUALITY OF EXTRUSION
}

The article highlights one of the ways to improve the design of the extruder body in order to increase the reliability and, at the same time, the quality of extrusion. The object of research is a single-worm extruder. One of the most problematic areas of the extruder is the body. The main disadvantage of the extruder is the wear of the body surfaces due to corrosion or abrasion and requires regular replacement. This is due to the abrasive properties of the polymers and, accordingly, due to the friction of the polymer material against the body and the worm, especially due to contamination in the recycled material. In various sources, the replacement of the extruder worm with a more advanced design is widely covered. And scientists do not pay enough attention to improving the body of the extruder, which indicates the relevance of this study. That is why the problem of increasing the reliability of the extruder body is completely unsolved and urgent. In the course of the study, we used an analysis of the structural features of the extruder body, a literature-patent review of existing methods for improving the body of a single-worm extruder to increase the reliability and, at the same time, the quality of extrusion. As a result of the literature and patent review, the option of improving the extruder body based on the prototype of the split body, which additionally contains an inner surface of steel ribbed plates, was selected. It was found that the ribbing of the plates on the inner surface of the body increases the wear resistance of the body and promotes more intensive advancement of the polymer used material to the extruder head. This is due to the fact that the proposed improved body of the extruder has a number of features: steel ribbed plates rigidly fixed inside it are installed with overlap of the parting line of the extruder body. This makes it possible to increase the wear resistance and, accordingly, the reliability of the extruder body and, additionally, the extrusion quality. Compared with the known one-piece structures of the extruder body, the design of the body is detachable with steel rigidly mounted ribbed plates on the inner surface, which will simplify maintenance during repairs and, at the same time, improve the quality of extrusion.

Keywords: extruder, improvement of the extruder body, finning of the plates, extrusion quality, wear of the extruder body, extruder worm.

\section{How to cite}

Kazak, I. (2021). Improvement of the extruder body design in order to increase reliability and quality of extrusion. Technology Audit and Production Reserves, 4 (1 (60)), 15-19. doi: http://doi.org/10.15587/2706-5448.2021.237539

\section{Introduction}

Modern requirements in chemical, polymer and other industries are characterized by dynamism, which is dictated by the sensitivity to trends in the production of quality products, which depends, inter alia, on reliable equipment on extrusion lines. The relevance of this study is that single-worm extruders are used as the main component of extrusion lines, which, depending on the type of forming tool and the composition of other components of the line can produce films, pipes and other profiles, sheets, etc. extruder is a type of extrusion technique that provides processing of plastics into products by extrusion [1]. The peculiarity of this equipment is that only one worm is used in the extruder. This arrangement, in contrast to two-worm or multi-worm, as well as various special extru- ders, is the simplest and used in real conditions of chemical, polymer and other modern industries. Therefore, the author of this paper proposes to consider one of the ways to improve the design of the body of a single-worm extruder in order to improve the reliability and quality of extrusion.

The solution to the problem of increasing the reliability of extruders is considered by scientists for various industries, including chemical engineering. Timely replacement of parts and assemblies prone to wear under the influence of friction, ensures stable operation of the press extruder and preserves the quality of the product.

The source [2] offers a solution to the problem of increasing the reliability of extruders in the agricultural sector by improving the working body (pressing unit). This is done by replacing the left-hand stud on the loading side of the operating device. As a result reliability of work is 
provided, accordingly, resource consumption, productivity of a press extruder increases.

The authors in the source [3] propose the implementation of the folding body of the extruder in thickness and sleeve to ensure the durability of the body. The folding case will provide an opportunity of repair at the expense of replacement of a sleeve. Usually the sleeve is made motionless and fastened with locking worms or dowels, or by landing with tension. It is also possible to install the sleeve in the body without tension to facilitate its replacement. The thickness of the sleeve is chosen based on design features taking into account the location of the locking elements.

To increase the reliability and quality of extrusion in the source [4], the design of the detachable body of the extruder with steel ribbed plates from the inner surface is considered. This increases the wear resistance of the extruder body and additionally more stable movement of the material on the extruder body and improves the quality of extrusion.

Also, one of the ways to improve the body of a singleworm extruder and increase its reliability is proposed in the source [5], in which the new design of its removable mixing section provides rapid replacement of the most vulnerable elements: abutment rings of antifriction heat-resistant material (for example, bronze). This design increases the reliability and maintainability of the extruder, as well as contributes to the absence of stagnant zones and the receipt of quality products by the extruder of a given performance.

A very similar approach to increasing the reliability of the extruder body is used by the authors in the source [6] and emphasizes the design features of extruder cylinders, which are usually made of steel 40 or $40 \mathrm{X}$, and to ensure wear resistance is inserted into a steel sleeve Usually the sleeve is made of harder materials than the worm. It is also possible to manufacture the extruder body without a sleeve. In this case, a wear-resistant material is deposited on the inner surface of the extruder body.

The source [7] proposes an improvement of a singleworm extruder, in which in the area of low pressure of the channel of the extruder warm contains at least one cleaning element. This cleaning element is located next to the vent for removing volatile substances or with an additional loading hole. This cleaning element facilitates the reliable advancement of the component of the mixture in the extruder. This method of improving the extruder body is particularly useful in the field of current mixing, where the preparation of the melt with impurities requires a device for adding them in several stages.

There is also a method of improving the extruder [8], in which the extruder body is divided into two chambers, of which the front chamber has a feed hole, and the rear chamber has at least one exhaust hole for removing gases and an outlet. Both chambers are communicated with each other by a channel in which the melt filter is located. The imaginary extension of the longitudinal axis of the worm passes against the direction of transport of the worm along the axis of rotation. The longitudinal axis on the outlet side is offset by a distance from the radial of the hopper, which is parallel to the longitudinal axis. The length $(L)$ of the auger in the front chamber is $10-40$-fold, and the distance from the inlet of the channel into the rear chamber to the exhaust hole 1.5-15-fold nominal diameter $(d)$ of the auger. This design of the extruder body provides increased stability and, consequently, reliability and increases the productivity of material processing.

The source [9] discusses the problem of extruder's reliability based on extrusion dies, which are made of hot working tool steels, and they can fail due to various modes of destruction, such as wear, cracking and mechanical and thermal fatigue. Taking into account the average value and variance during the life of the matrix, the nature of the frequency of their failure is investigated and the corresponding characteristic of reliability is given. On the basis of reliable life modeling on the basis of experimental data the interpretation of quality of the tool and its characteristics taking into account function of losses is also provided.

Thus, it can be noted that in the sources $[2,5]$ it is proposed to increase the reliability of the extruder body by replacing individual wear elements in different areas of the extruder body (pins in the loading area, support rings made of heat-resistant materials). In scientific works $[3,4,6]$ the improvement of the extruder body is the use of different designs of the sleeve to increase the reliability of the body. In works $[7,8]$ it is proposed to create various cleaning elements or holes in the body of the extruder to improve its reliable operation and quality of extrusion. The source [9] proposes one of the ways to improve the extruder based on modeling the life cycle of matrices, which will predict the reliability of its operation on the basis of experimental data.

As the analysis of the considered literature and patent sources shows, most scientists offer various ways to improve the design of the extruder body for more reliable operation of the extruder with additional high-quality extrusion. It is based on this analysis of the problem of reliability of extruders, it is possible to conclude that this issue is not fully resolved by scientists and in various aspects. Therefore, the problem of increasing the reliability of extruders can't be considered completely solved, which confirms the relevance of the study in the work.

Thus, the object of research is the extruder body. And the aim of research is to choose a way to improve the body of a single-worm extruder to increase its reliability with further improving the quality of extrusion. To achieve this aim, the following objectives were solved: to identify possible ways to improve the design of a single-worm extruder.

\section{Methods of research}

The process of obtaining products by forcing (extruding) the material through the molding hole in the matrix or series of matrices is called extrusion (from the Latin extrusio - «pushing») $[10,11]$. Extrusion is currently carried out mainly on single-worm presses. In addition, the machine includes cooling, traction, cutting and other devices. Single-worm extruders have received the greatest application because they are relatively simple, cheap and easily give a continuous yield of finished products. The worm and the body are two parts of the extruder that interact to transport the plastic material, melting the material, and then push it through the die. The ability of the worm and the body in the extrusion of this material depends on the characteristics of the extruded material, the characteristics or design of the worm and the extruder body, as well as the conditions under which the system operates [11]. 
The worm press consists of the following units: loading pipe 1, material cylinder (extruder body) 2, adapter 3 and adapter ring (mandrel) 4, forming tool (extrusion head) 5 , worm 6 , heaters 7 , electric drives 8,9 , reducer 10 (Fig. 1) [1].

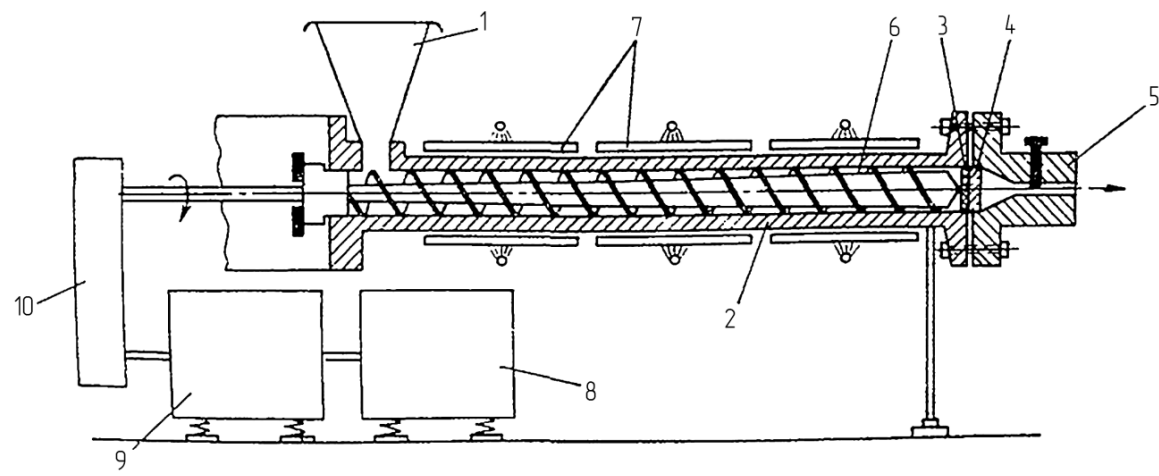

Fig. 1. The design of a single-worm extruder:

1 - loading pipe; 2 - material cylinder (extruder body), consisting of three or more zones (supply, plasticization and dosing); 3, 4 - adapter, adapter ring or other device for transferring the molten polymer mass from the extruder to the forming tool; 5 - forming tool (extrusion head); 6 - worm;

7 - ring heaters of the material cylinder; 8, 9 - electric drives; 10 - reducer in the loading area, it will be difficult or impossible to move the material forward.

One of the main components of the extruder is the body 2 . There are several types of extruder body: separate, collapsible in length, integral, body with a loading funnel. Small worm extruders still use body design options, such as a thickwalled torque-immersed cylinder that is transmitted from the worm by axial force from the pressure in the material. Or axial force from the torque on the worm and with the bending moment in the cantilever structure of the case.

Based on the above, and that the body is one of the most important components in the extruder, there is a strong need to pay attention to ways of increasing the reliability of the extruder body to ensure its wear resistance by rubbing the source material against the walls of the material cylinder during its continuous operation.

The worm 6 takes the unplasticized material from the loading pipe 1 and simultaneously feeds it in the form of a homogeneous melt to the extruder head 5. As approaching the extruder head to compensate for changes in volume and density during the transition of thermoplastic from solid to molten state, cross-sectional area the worm should decrease. This is achieved by reducing the depth of the worm's canal. During operation, the worms are exposed to elevated temperatures, the products of destruction are processed, as well as the abrasive action of solid particles that accidentally got into the material. In these harsh conditions, the worm must withstand abrasion for a long time, as well as the effects of the twisting effect, so for the manufacture of worms used corrosion-resistant alloy steel 40X. One of the most important characteristics of a worm extruder is the ratio of the length of the worm $L$ to its diameter $d$. Usually in worm machines designed for plastics processing, the $L / d$ ratio is in the range of $20-25$ [12].

The body of the extruder is a cylindrical chamber in which the worm rotates and moves the thermoplastic material. For small diameter extruders, the material cylinder (extruder body) is usually made solid. The cylinder of large presses is formed from the external case from high-strength steel and the sleeve from corrosion-wearresistant steel is inserted inside. A sufficiently tight contact must be provided between the sleeve and the enclosing body so that a uniform heat flow can be achieved. To give such a structure the necessary rigidity, the sleeve is usually pressed into the cylinder of the press, and to prevent the sleeve from overturning during operation, pins are inserted. The inner surface of the sleeve should not be too smooth and polished. This is necessary to ensure the highest possible coefficient of friction for the incoming raw material and rubs against the wall of the sleeve. The extruder body is heated by electric current. To do this, use heaters 7 induction or ohmic type. The loading area is usually cooled. This is necessary so that there is no overheating of the mass in the loading area and that there is no adhesion of the mass of the thermoplastic and sticking to the worm. If the material is not cooled

\section{Research results and discussion}

As a result of the literature-patent review and analysis of directions of improvement of a design of the single-worm extruder the following features of the offered technical decisions are revealed:

- replacement of most often wearing parts (a pin, a bearing ring in a loading zone, matrices in an initial part of an extruder, etc.), which is characteristic only for increasing the reliability of the extruder [2, 5, 9]; - installation in different areas of the extruder cleaning elements or holes for the organization of the current mixing in the process of preparation of the melt with impurities for their addition in several stages, which contributes to a more reliable and high-quality manufacture of polymer products [7];

- execution of the extruder body of two chambers, which are communicated with each other by a channel with a melt filter and the second chamber has a hole for gas removal, which will increase the stability and productivity of material processing [8];

- modeling based on experimental data of failure frequency of extruder matrices as a result of wear, cracking, mechanical and thermal fatigue and providing appropriate characteristics of reliability and prediction of matrix service life [9], which is not always possible without sufficient experimental information on the machine and knowledge and modeling skills;

- manufacturing a body made of heat-resistant steel 40 or $40 \mathrm{X}$, and a sleeve made of steel $38 \mathrm{X} 2 \mathrm{M} 10 \mathrm{~A}$ or its analogues with appropriate heat treatment to ensure wear resistance of the body, it is also possible to make the extruder body without sleeve and with surfacing on its inner part wear-resistant material [6];

- execution of the extruder body folding, not integral and with a sleeve, which will increase the reliability and the possibility of replacing the sleeve during its wear [3, 4].

To choose a method of improving the design of the extruder, let's take into account the features of the considered 
possible design solutions for improving the extruder in order to improve the reliability and quality of extrusion and diminish the main disadvantages of extruders. The most common disadvantage of extruders for the manufacture of pipes is the high wear of the inner surface of the extruder body and as a consequence there is a decrease in the reliability and quality of extrusion. Also another disadvantage for the integral design of the extruder body is the difficulty in its maintenance.

As a result of literature-patent search [3, 4, 6] of design features and principle of single-worm extruders as the most common type in the production of various industries, the choice of the most appropriate in our opinion design of the extruder body to increase its reliability with steel ribbed sleeve. To eliminate such disadvantages of extruders as low reliability and reduced extrusion quality, a prototype of the extruder body is selected, which is made in the form of a hollow cylinder with the possibility of separation into two parts in a plane passing through the longitudinal axis of symmetry of the body. The advanced body with a loading hole further comprises a set of plates made of hardened steel, repeating the shape of the inner surface of the extruder body and rigidly mounted inside it.

The plates are installed with the overlap of the connector line of the extruder body, while the sides of the plates facing the longitudinal axis of symmetry of the extruder body are made with ribs [4].

Fig. 2 shows the design of the extruder with an improved body (front view). Fig. 3 shows a cross section $\mathrm{A}-\mathrm{A}$ of the advanced body of the extruder.

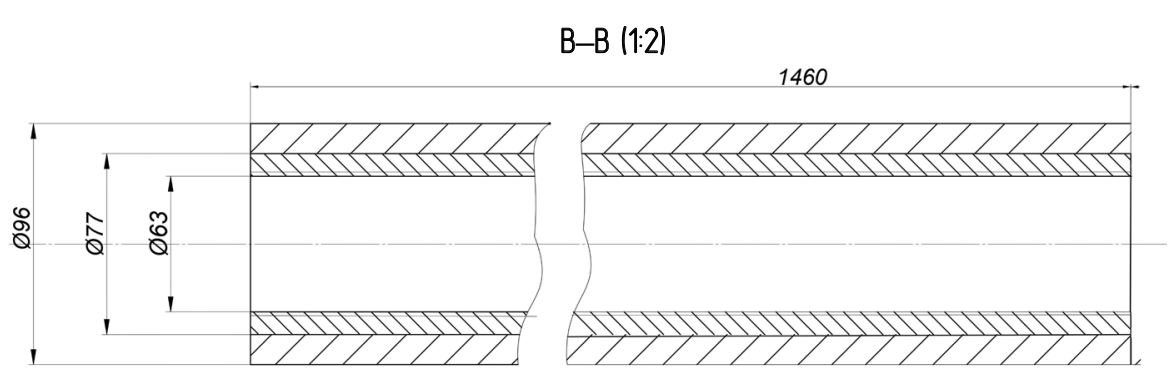

Fig. 4. Longitudinal section of the improved design of the extruder body

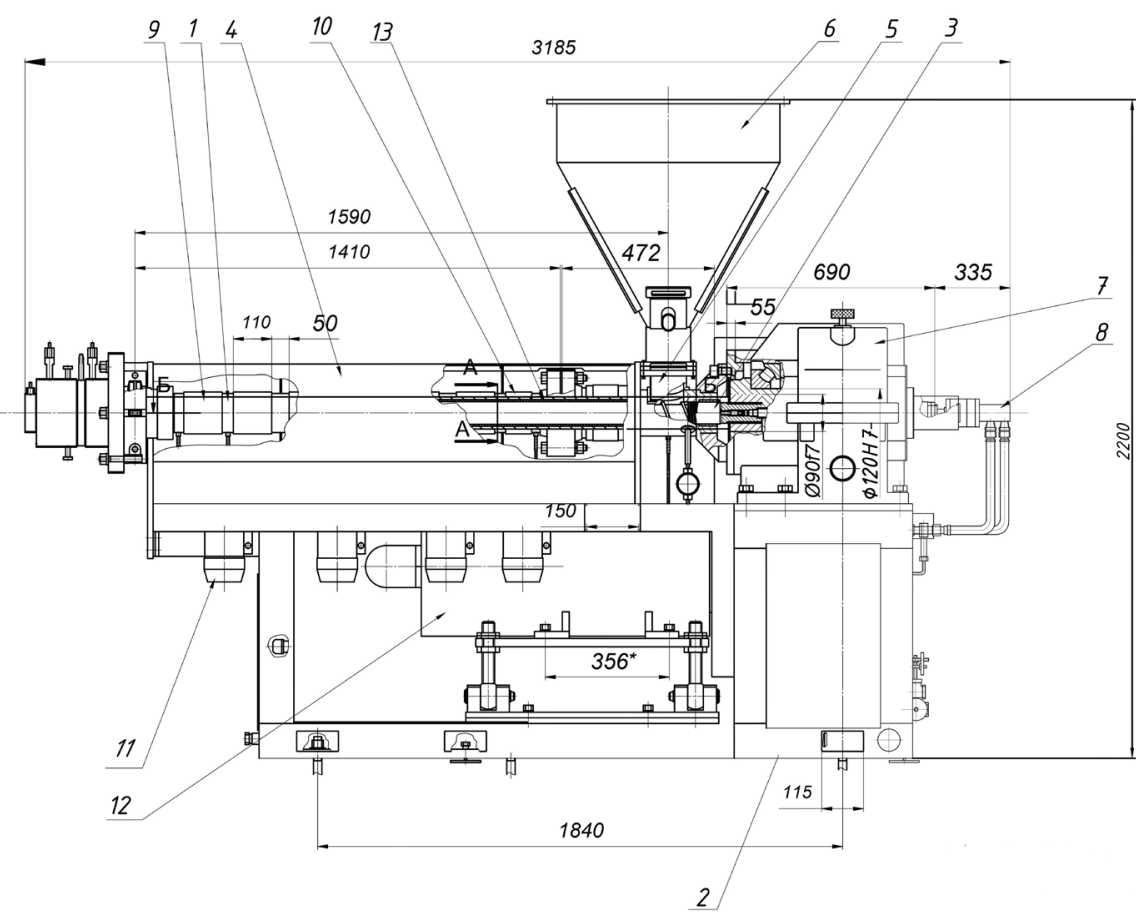

Fig. 2. Extruder with an improved body design of rigidly mounted steel ribbed plates (front view): 1 - extruder cylinder; 2 - frame; 3 - worm; 4 - body; 5 - loading funnel; 6 - loading branch pipe; 7 - reducer; 8 - worm cooling device; 9, 10 - induction heaters; 11 - fan; 12 - electric motor; 13 - steel plates
The advanced extruder consists of: extruder cylinder 1 , frame 2 , worm 3 , body 4 , loading funnel 5 and loading pipe 6 . The extruder also includes a reducer 7 , a worm cooling device 8 , induction heaters 9 , 10, fan 11 , electric motor 12, steel ribbed plates 13 .

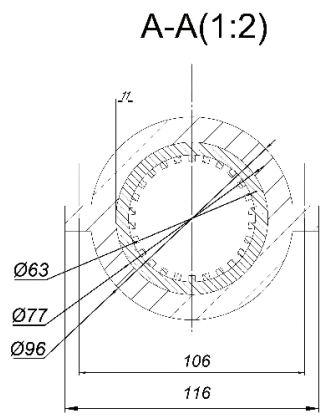

Fig. 3. Cross section of the advanced design of the extruder body with ribbed steel plates inside

Fig. 4 shows a longitudinal section $\mathrm{B}-\mathrm{B}$ of an improved design of the extruder body with ribbed steel plates on its inner surface.

The improved design of the extruder body is a hollow cylinder 1 with the possibility of separation into two parts in a plane passing through the longitudinal axis of symmetry of the body 4 with the loading pipe 6 . The proposed body design has rigidly fixed inside steel ribbed plates 13 extruder body. The plates 13 face the longitudinal axis of symmetry of the body and are fixed with the overlap of the connector line of the extruder body and are made with ribs. The fastening elements of the plates to the body are not shown in the drawings, nor are the fastening elements of the body parts to each other.

Due to the installation in the body of the extruder 4 of the ribbed steel plates 13 on the inner surface provides an increase in wear resistance of the improved body, and accordingly its reliability. Also, the finning of the plates allows for additional stable advancement to the output of the 
extruded material, which increases the quality and reliability of extrusion.

Thus, one can choose a detachable body with ribbed steel rigidly fixed plates on its inner surface as a prototype. This design of the inner surface of the body will increase the wear resistance and, accordingly, reliability with additional stable advancement of the source material from the loading zone to the extrusion head, which improves the quality of extrusion. Also, the design of the detachable body design will simplify the maintenance of the extruder.

\section{Conclusions}

The study revealed a few possible ways to improve the design of a single-worm extruder based on the body as one of the wearing parts. Among the problems considered in the study to increase the reliability and quality of extrusion there was chosen as the most appropriate and effective in our opinion way to improve the extruder body based on the prototype body [4], which is made inside with ribbed plates of hardened steel. The method chosen in the work to improve the extruder body is made graphically in an automated design system in front, top and side views for clarity of the representation of such a structure. As evidenced by the authors of the prototype selected by us in this work, the implementation of an improved extruder body detachable with rigidly fixed steel ribbed plates on its inner surface increases its wear resistance and more intensive advancement of material on the body due to finning of the plates, respectively service during repairs.

The advantage of the chosen method of improving the extruder in comparison with possible other areas of improvement considered in the study is that when performing the body as one of the constantly worn by friction material parts of steel ribbed plates inside and detachable, allows not only to increase reliability but also further improve the quality of extrusion while simplifying the maintenance of the extruder.

Further research is planned to analyze the areas of improvement of the extruder in the wear of the worm, as the second working part in interaction with the body and also subject to constant wear due to friction of the material and thermal effects of the polymer melt.

\section{References}

1. Odnoshnekoviy ekstruder (odnochervyachniy ekstruder). Slovar terminov. PlastEkspert - vse o plastikakh i polimerakh. Available at: https://e-plastic.ru/slovar/o/odnoshnekovyi_extruder/

2. Kushnir, V. G., Gavrilov, N. V., Shkotova, T. V., Borzenkov, A. P. (2019). The extruder improvement. Journal of VNIIMZH, 3 (35), $56-60$.

3. Sivetskyi, V. I., Kurylenko, V. M., Ivitskyi, I. I. (2018). Tekhnolohichne obladnannia vyrobnytstva budivelnykh ta polimernykh vyrobiv - 1. Obladnannia budivelnykh materialiv $i$ vyrobiv. Laboratornyi praktykum z navchalnoi dystsypliny. Kyiv: KPI im. Ihoria Sikorskoho, 45. Available at: https://ela.kpi.ua/handle/ $123456789 / 25137$

4. Kostin, V. V., Pogorelskaya, O. I., Simonenko, V. I. (2011). Pat. No. RU 103446 U1. Korpus ekstrudera. MPK: A23 N17/00 (2006.01). No. 2010140649/13; declareted: 10.04.2010. published: 20.04.2011, Bul. No. 11

5. Kuzmina, V. O., Mikulonok, I. O., Shved, D. M., Shved, M. P. (2010). Pat. No. 54940 UA. Odnochervnyi ekstruder. MPK: B29 C47/36, B29 B7/34 (2009). No. u201007330; declareted: 14.06.2010; published: 25.11.2010, Bul. No. 22.

6. Mikulonok, I. O., Sokolskyi, O. L., Sivetskyi, V. I., Radchenko, L. B. (2015). Osnovy proektuvannia odnocherviachnykh ekstruderiv. Kyiv: NTUU «KPI», 2015, 200.

7. Makdonald, D., Mortazavi, A., Kreyg, D., Ilmonen, R., Gau, D. (2009). Pat. No. RU 2350467 C2. Usovershenstvovanniy ekstruder v sbore. MPK B29C 47/38 (2006.01). No. 2007117929/12; declareted:14.09.2007; published: 27.03.2009, Bul. No. 9.

8. Feykhtinger, K., Khakl, M. (2016). Pat. No. RU 2577383 C2. Ustroystvo dlya pererabotki polimernogo materiala. MPK: B29B17/04. No. 2014119281/05; declareted: 12.10.2012; published: 20.03.2016, Bul. No. 8

9. Sheikh, A. K., Younas, M., Arif, A. F. M., Gasem, Z. (2011). Reliability and performance evaluation of extrusion dies. International Journal of Reliability and Safety, 5 (1), 21. doi: http:// doi.org/10.1504/ijrs.2011.037345

10. Ekstruziia. Available at: https://uk.wikipedia.org/wiki/Екструзія

11. Goff, J., Whelan, T.; DeLaney, D. (Ed.) (2000). The Dynisco Extrusion Processors. DYNISCO. Available at: https://www. dynisco.com/userfiles/files/27429_Legacy_Txt.pdf

12. Ekstruziya termoplastov (2012). Available at: http://plastichelper.ru/biblioteka-on-line-about-polimers/52-technologyof-polimers/239-422-ekstruziya-termoplastov

Iryna Kazak, PhD, Associate Professor, Department of Chemical, Polymer and Silicate Mechanical Engineering, National Technical University of Ukraine «Igor Sikorsky Kyiv Polytechnic Institute», Kyiv, Ukraine, e-mail: AsistentIA@meta.ua, ORCID: http://orcid.org/ 0000-0001-9450-8312 